\title{
A STUDY OF CARBON DIOXIDE-DEPENDENT STRAINS OF STREPTOCOCCUS MILLERI
}

\author{
Penelope R. Sisson, H. R. Ingham and J. B. Selkon \\ Regional Public Health Laboratory, General Hospital, Newcastle upon Tyne NE4 6BE
}

IN THIS laboratory all bacteria isolated on anaerobic culture that fail to grow under strictly aerobic conditions are routinely tested to determine their sensitivity to metronidazole, an agent that is specifically active against obligate anaerobes (Prince et al., 1969; Fuzi and Czukas, 1970). This procedure has revealed a group of metronidazole-resistant non-haemolytic Gram-positive streptococci that on further investigation were shown to be facultative anaerobes, capable of growing aerobically only in the presence of carbon dioxide.

A preliminary examination of the characteristics of these strains indicated that they belonged to the species Streptococcus milleri and eight out of nine strains tested possessed the Lancefield group- $\mathrm{F}$ antigen; the remaining strain did not react when extracts were tested with group A, C, F or G antisera. $S$. milleri, as currently defined, includes strains that are either not groupable or individually possess the Lancefield group antigens $\mathrm{A}, \mathrm{C}, \mathrm{F}$ or $\mathrm{G}$, the group F antigen occurring in only $23 \%$ (Facklam, 1977) to $30 \%$ (Colman and Williams, 1972). In view of these observations a larger number of $\mathrm{CO}_{2}$-dependent strains were studied.

\section{MATERIALS AND METHODS}

Techniques of primary isolation. Specimens of pus and wound swabs were inoculated on blood agar $\left(5 \%\right.$ horse blood in Oxoid Blood Agar Base) and incubated at $37^{\circ} \mathrm{C}$ for up to $48 \mathrm{~h}$ aerobically and anaerobically in an atmosphere consisting of hydrogen $(90 \%)$ and carbon dioxide $(10 \%)$ in an anaerobic jar fitted with a cold catalyst. Routine high vaginal swabs were also inoculated on blood agar containing nalidixic acid $50 \mu \mathrm{g}$ per $\mathrm{ml}$ to assist in the isolation of streptococci, and incubated anaerobically for $48 \mathrm{~h}$ by the technique described above. Urine samples were examined within $1 \mathrm{~h}$ of collection and cultured quantitatively, with a fused platinum-iridium loop delivering $0.001 \mathrm{ml}$, on blood agar and MacConkey Agar (Oxoid) incubated aerobically and anaerobically. Blood was cultured by adding $10 \mathrm{ml}$ to Brain Heart Infusion Broth (Oxoid) containing $0.03 \%$ sodium polyanethol sulphonate.

Stained slides prepared from colonies that grew only under anaerobic conditions were examined microscopically, and all Gram-positive cocci were subcultured on blood agar and their sensitivity to metronidazole was determined by means of a filter paper disk containing metronidazole $5 \mu \mathrm{g}$. Strains growing up to the metronidazole disk were subcultured on blood agar plates incubated for 5 days either in air, or in air with $\mathrm{CO}_{2}(5 \%$ and $10 \%)$, or anaerobically in pure hydrogen without added $\mathrm{CO}_{2}$.

Biochemical methods. The ability of each strain to ferment a range of carbohydrate substrates was examined by means of Peptone Water (Evans) containing test carbohydrate $1 \%(\mathrm{w} / \mathrm{v})$ and Andrade's indicator $1 \%(\mathrm{v} / \mathrm{v})$. The seeded media were incubated for 3 days in air with $\mathrm{CO}_{2}(10 \%)$.

Received 14 July 1977; accepted 3 Sept. 1977.

J. MED. MICROBIOL. - VOL. 11 (1978) 
Each strain was grown on nutrient agar to test for catalase. A little of the growth was removed from the surface of the agar with a coverslip, and then immersed in $3 \%$ hydrogen peroxide. A positive reaction was indicated by the production of bubbles.

All strains were tested for their ability to hydrolyse arginine and aesculin and to grow on $10 \%$ bile agar and in $4 \% \mathrm{NaCl}$ Hartley broth.

The isolates were identified by the criteria of Colman and Williams (1972) and by reference to Cowan and Steel (1974).

Serological grouping was carried out by the precipitation technique of Lancefield (1933). Cultures in Todd-Hewitt Broth (Oxoid) were incubated in air with $\mathrm{CO}_{2}(10 \%)$ at $37^{\circ} \mathrm{C}$ for $18 \mathrm{~h}$ and each strain was tested against Lancefield group A, C, F and G antisera (Burroughs Wellcome Ltd) in capillary tubes that were examined for up to $30 \mathrm{~min}$. for a precipitation reaction. S. milleri strain NCTC10707 was used as a control in all tests.

In addition, Lancefield grouping was carried out on a group of 20 streptococci that grew well anaerobically but, on primary isolation, grew poorly in air.

Sensitivity tests were carried out by the disk diffusion method on blood agar plates, uniformly inoculated with a wire loop to give semi-confluent surface growth. Mast antibiotic disks containing penicillin 1 unit, bacitracin $0 \cdot 1$ unit or metronidazole $5 \mu \mathrm{g}$ were used. In addition, the minimal inhibitory concentration (MIC) of penicillin for the strains studied was determined by incorporating doubling dilutions of penicillin in blood agar plates, and inoculating the plates with a loopful $(0.001 \mathrm{ml})$ of an overnight broth culture of each strain. The plates were incubated in air containing $\mathrm{CO}_{2}(10 \%)$ and examined after 2 days.

\section{RESULTS}

Forty-four strains of $\mathrm{CO}_{2}$-dependent streptococci were isolated from a variety of sites (table). The presence of $\mathrm{CO}_{2}(10 \%)$ was necessary for optimal growth, as indicated by colony size, under both anaerobic and aerobic conditions. All strains were resistant to bacitracin and sensitive to penicillin, the MIC of penicillin for 31 strains being $0.08 \mu \mathrm{g}$ per $\mathrm{ml}$ and for the remainder $0.04 \mu \mathrm{g}$ per ml.

\section{TABLE}

Source of isolates

\begin{tabular}{l|c}
\hline \multicolumn{1}{c|}{ Source } & Number of isolates \\
\cline { 2 - 2 } $\begin{array}{l}\text { Wounds } \\
\text { Abdominal } \\
\text { Other }\end{array}$ & 12 \\
Genito-urinary & 2 \\
$\quad$ Vagina & \\
$\quad$ Urinary tract & 18 \\
Abscesses & 2 \\
$\quad$ Dental & \\
Brain & 3 \\
Liver & 2 \\
Perianal & 1 \\
Apprapubic & 1 \\
Blood & 1 \\
Total & 1 \\
\hline
\end{tabular}




\section{Morphology}

Colonial morphology was variable but most strains produced small greywhite glossy colonies on blood agar plates after 2 days' incubation in air with $\mathrm{CO}_{2}(10 \%)$. No strain was $\beta$-haemolytic on horse blood agar, but four produced $\alpha$-haemolysis, though somewhat inconstantly.

Microscopical examination of smears from the colonies of all strains showed small Gram-positive cocci in short chains, often with coccobacillary forms.

\section{Biochemical characteristics}

All 44 strains fermented glucose, lactose, sucrose, maltose, salicin and trehalose. None fermented mannitol or dulcitol and only two fermented raffinose. All were catalase negative and none grew in $4 \% \mathrm{NaCl}$ broth. All the strains hydrolysed arginine and aesculin, and grew on $10 \%$ bile agar. Cultures of 39 of the isolates had a distinctive caramel odour, especially on freshly-incubated blood-agar plates.

\section{Serological grouping}

Forty $(90 \%)$ of the strains gave a precipitation reaction with Lancefield group-F antiserum, and did not cross react with the other Lancefield grouping sera used. The remaining four strains gave no reaction with A, C, F or G antiserum.

Eighteen of the additional group of 20 isolates of streptococci that grew poorly in air on primary isolation, gave no reaction with group $\mathrm{A}, \mathrm{C}, \mathrm{F}$ or $G$ antiserum. The remaining two gave a precipitation reaction with the Lancefield group- $\mathrm{F}$ antiserum. Both these isolates produced small $\beta$-haemolytic colonies on horse blood agar, failed to ferment lactose or hydrolyse aesculin and were identified as $S$. anginosus.

\section{Discussion}

The critera used for the selection of streptococci for this study were inability to grow aerobically in the absence of added $\mathrm{CO}_{2}$ and resistance to metronidazole when grown anaerobically. Whilst all strains grew on blood agar plates incubated anaerobically, the largest colonies were obtained by growth in air with $\mathrm{CO}_{2}(10 \%)$ or hydrogen with $\mathrm{CO}_{2}(10 \%)$. Growth was poor in air with $5 \% \mathrm{CO}_{2}$. After repeated subculture over a period of several months some strains gave slight growth under aerobic conditions without added $\mathrm{CO}_{2}$. These findings indicate that the strains have a genuine requirement for an increased concentration of $\mathrm{CO}_{2}$. This contrasts with Haemophilus and Bacteroides spp., whose growth is stimulated by, but is not dependent upon, the presence of $\mathrm{CO}_{2}$. The 44 strains exhibited remarkably uniform cultural, biochemical and, in particular, antigenic characteristics and would currently be classified as $S$. milleri.

"S. milleri" was first proposed by Guthof (1956), and Colman and Williams 
(1972) included in it a group of strains that fermented lactose, sucrose, trehalose and salicin, hydrolysed arginine and aesculin and were resistant to bacitracin and nitrofurazone. Few of their 42 strains of $S$. milleri grew at $45^{\circ} \mathrm{C}$ or in $4 \%$ $\mathrm{NaCl}$ broth, fermented raffinose or inulin, or hydrolysed starch; $23(55 \%)$ possessed Lancefield group A, C, F or G antigens, the remainder being nongroupable. The presence of several distinct antigenic types may point to heterogeneity within the species, but somewhat against this is the observation by Colman and Williams (1965) that the cell-wall residues of non-haemolytic streptococci with $\mathrm{A}, \mathrm{C}$ or $\mathrm{G}$ group antigens were chemically similar to those from non-haemolytic group-F streptococci and those from the strains of S. milleri of Guthof (1956).

In the present study $90 \%$ of the strains possessed the group $\mathrm{F}$ antigen, compared with only one-third of the $S$. milleri strains of Colman and Williams (1972). Parker and Ball (1976) found that $7 \%$ of their S. milleri strains had the group $\mathrm{F}$ antigen, $13 \%$ had $\mathrm{A}, \mathrm{C}$ or $\mathrm{G}$, whilst $80 \%$ were ungroupable, but their strains included "minute" haemolytic streptococci that could have been $S$. anginosus. Clearly, if strains are selected on the basis of complete $\mathrm{CO}_{2}$-dependence for aerobic growth, the resulting collection will be a group of isolates biochemically indistinguishable from $S$. milleri, but antigenically more homogeneous than the $S$. milleri strains of Colman and Williams (1972).

The additional group of 20 isolates of streptococci that were facultative anaerobes and grew poorly in air contained only two with the group F antigen, and these conformed with the description by Long and Bliss (1934) of " minute" haemolytic streptococci. Whilst Colman and Williams (1972) considered these to be variants of $S$. milleri, such strains continue to be known as "minute haemolytic streptococci" or S. anginosus (Koepke, 1965).

Little is known of the natural habitat of $S$. milleri. The organism appears to be a common inhabitant of the human dental-root canal (Ottens and Winkler, 1962) and appendix (Rogers, 1957), but studies of the other possible carrier sites have not been made. Many of the strains in this study came from high vaginal swabs of healthy women, and it seems likely that this is another site in which they are commensals.

S. milleri has been isolated from pyogenic liver abscesses (Bateman, Eykyn and Phillips, 1975; Reid and Davidson, 1976) and was reported by Parker and Ball (1976) to be most often isolated from purulent lesions in internal organs, being associated with brain abscess, meningitis, pleural empyema and a variety of intra-abdominal abscesses. A similar distribution was found in this study, and whilst many of the abdominal isolates were from mixed bacterial infections, it is noteworthy that some isolates, including the two from brain abscesses and one from the liver, were recovered in pure culture, leaving little doubt of the pathogenicity of the species under certain circumstances.

In a recent study of the ecology of group $\mathrm{F}$ streptococci, Bannatyne and Randall (1977) found that the growth of non-haemolytic group-F streptococci was neither dependent on, nor enhanced by, increased concentrations of $\mathrm{CO}_{2}$, and the cultures lacked a caramel odour. This has not been our experience with 44 strains, but that may be a reflection of differences in methods, in 
particular in the selection of strains studied. Bannatyne and Randall (1977). commented on the frequent isolation of group $F$ streptococci from dental abscesses, but the role of these organisms in such infections is not clear in view of recent work implicating obligate anaerobes as the primary pathogens. (Ingham et al., 1977).

Further information concerning the role of $\mathrm{CO}_{2}$-dependent streptococci in human infections will require the more widespread application of cultural techniques that permit their isolation and subsequent identification. Parker and Ball (1976) observed that many of the strains sent to them for identification had been regarded as anaerobic streptococci. As anaerobic streptococci are virtually always sensitive to metronidazole (Nastro and Finegold, 1972), any metronidazole-resistant strains of Gram-positive cocci failing to grow aerobically should be checked for their ability to grow in $5 \%$ and $10 \% \mathrm{CO}_{2}$ in air, and Lancefield grouping should be carried out. The use of pre-reduced blood-culture media or media gassed with $\mathrm{CO}_{2}(10 \%)$ might well increase the numbers of $\mathrm{CO}_{2}$-dependent streptococci isolated from blood. The application of such techniques may help to elucidate the role of these organisms in human infections.

\section{SUMMARY}

Forty-four strains of non-haemolytic streptococci, from a variety of sites, that required $\mathrm{CO}_{2}$ for aerobic growth were identified as Streptococcus milleri. Of these strains, $40(90 \%)$ possessed the Lancefield group-F antigen, the remainder being non-groupable with antisera to the group antigens $\mathrm{A}, \mathrm{C}, \mathrm{F}$ and $\mathrm{G}$.

We are grateful to Dr S. P. Lapage for providing S. milleri strain NCTC10707 and to Dr M. T. Parker and Mrs L. C. Ball for their advice and encouragement.

\section{REFERENCES}

Bannatyne, R. M. and Randall, C. 1977. Ecology of 350 isolates of group F streptococcus. Am. J. clin. Path., 67, 184.

Bateman, N. T., Eykyn, S. J. And Phillips, I. 1975. Pyogenic liver abscess caused by Streptococcus milleri. Lancet, 1, 657.

Colman, G. and Williams, R. E. O. 1965. The cell walls of streptococci. J. gen. Microbiol., $41,375$.

Colman, G. AND Williams, R. E. O. 1972. Taxonomy of some human viridans streptococci. In Streptococci and streptococcal diseases: recognition, understanding and management, edited by L. W. Wannamaker and J. M. Matsen, New York and London, p. 281.

Cowan, S. T. And Steel, K. J. 1974. Manual for the identification of medical bacteria, 2nd ed., edited by S. T. Cowan, Cambridge.

FACKLAM, R. R. 1977. Physiological differentiation of viridans streptococci. J. clin. Microbiol., 5, 184.

Fuzi, M. AND CzuKas, Z. 1970. Das antibakterielle wirkungsspektrum des metronidazols. Zentbl. Bakt. ParasitKde, I. Abt. Orig., 213, 258.

GUTHOF, O. 1956. Über pathogene "vergrunende streptokokken". StreptokokkenBefunde bei dentogenin abszessen und infiltraten im bereich der mundhohle. Zentbl. Bakt. ParasitKde, I. Abt. Orig., 166, 553. 
Ingham, H. R., Hood, F. J. C., Bradnum, P., Tharagonnet, D. and Selkon, J. B. 1977. Metronidazole compared with penicillin in the treatment of acute dental infections. Br. J. oral Surg., 14, 264.

KoEPKE, J. A. 1965. Meningitis due to Streptococcus anginosus (Lancefield group F), J. Am. med. Ass., 193, 739.

LANCEFIELD, R. C. 1933. A serological differentiation of human and other groups of hemolytic streptococci. J. exp. Med., 57, 571.

LoNG, P. H. AND BuIss, E. A. 1934. Studies upon minute hemolytic streptococci. I. The isolation and cultural characteristics of minute beta hemolytic streptococci. J. exp. Med., 60, 619.

NASTRO, L. J. AND FInEgold, S. M. 1972. Bactericidal activity of five antimicrobial agents against Bacteroides fragilis. J. infect. Dis., 126, 104.

OTTENS, H. AND WINKLER, K. C. 1962. Indifferent and haemolytic streptococci possessing group-antigen F. J. gen. Microbiol., 28, 181.

Parker, M. T. AND Ball, L. C. 1976. Streptococci and aerococci associated with systemic infection in man. J. med. Microbiol., 9, 275.

Prince, H. N., Grunberg, E., Titsworth, E. and Delorenzo, W. F. 1969. Effects of 1-(2-nitro-1-imidazolyl)-3-methoxy-2-propanol and 2-methyl-5-nitroimidazole-1-ethanol against anaerobic and aerobic bacteria and protozoa. Appl. Microbiol., 18, 728.

ReID, T. M. S. AND DAvidson, A. I. 1976. Streptococcus milleri liver abscesses. Lancet, 1, 648.

Rogers, K. B. 1957. The association of acute appendicitis with infective diarrhoea. Proc. R. Soc. Med., 50, 1025. 